\title{
High-resolution Seismic imaging in the Santos Basin, Brazil and its impact on Salt Mechanics
}

H. Lebit, S. Arasanipalai, J. Tilton, P. Ollagnon, B. Virlouvet

Copyright 2019, SBGf - Sociedade Brasileira de Geofísica

This paper was prepared for presentation during the $16^{\text {th }}$ International Congress of the Brazilian Geophysical Society held in Rio de Janeiro, Brazil, 19-22 August 2019.

Contents of this paper were reviewed by the Technical Committee of the $16^{\text {th }}$ International Congress of the Brazilian Geophysical Society and do not necessarily represent any position of the SBGf, its officers or members. Electronic reproduction or storage of any part of this paper for commercial purposes without the written consent of the Brazilian Geophysical Society is prohibited.

\begin{abstract}
Innovative reprocessing of seismic data from the Santos Basin, Brazil produced enhanced seismic images that provide details on the presalt and postsalt architecture of the passive margin sequences and insights into the flow behavior of the Albian layered evaporite sequence (LES). The imaging reveals critical observations impacting the understanding of salt displacement at passive margins and the Santos Basin in particular, as well as offering enhanced risk mitigation for the basin's presalt hydrocarbon reservoirs. A domain approach underlines the major tectono-stratigraphic units, which are characterized by the architecture of the Aptian salt. It was found that displacement loading of a propagating sedimentary wedge at the Albian Gap caused lateral flow and thickness increase at the outboard salt sequence.
\end{abstract}

The study area comprises more than $34.000 \mathrm{~km}^{2}$ of single volume seismic broadband data, which represents the largest migration efforts Reverse Time Migration (RTM) and Kichhoff Prestack Depth Migration (KPSDM) successfully completed by the industry. Innovative LeastSquares Migration (LSM) is used to improve the resolution in imaging of the prolific pre-salt reservoirs.

\section{Introduction}

Located in the Santos Basin offshore Brazil (Mohriak et al. 2008) the study area comprises more than $44,000 \mathrm{~km}^{2}$ of high-resolution broadband seismic data, which have been calibrated by pre-salt well penetrations. The seismic dataset covers the Sao Paulo Plateau, a rift-related basement high that can be subdivided into three tectonostratigraphic domains based on the salt and post-salt architecture (Figure 1): The inboard northwestern domain characterizes the Albian Gap, an approximately $40 \mathrm{~km}$ wide zone of roll-over structures that apparently displaced most of the Aptian layered evaporite sequence (LES) and largely lacks the post-salt Albian carbonates. The Albian Gap terminates along predominately counter-regional normal faults against a thickened section of Aptian LES. This tick salt sequence is frequently disrupted by down building mini basins that occasionally weld against presalt sequences. Highly reflective layers of Anhydrite and other evaporites within the LES indicate complex internal folding while rather transparent sections are interpreted as accumulations of intra-formational mobilized halite. The occurrence of mini basins diminishes in the adjacent, outboard extensional domain that reveals increasingly well imaged folds within the LES which are gradually transient into asymmetric and then upright folds towards the distal section of this domain (Figure 2).

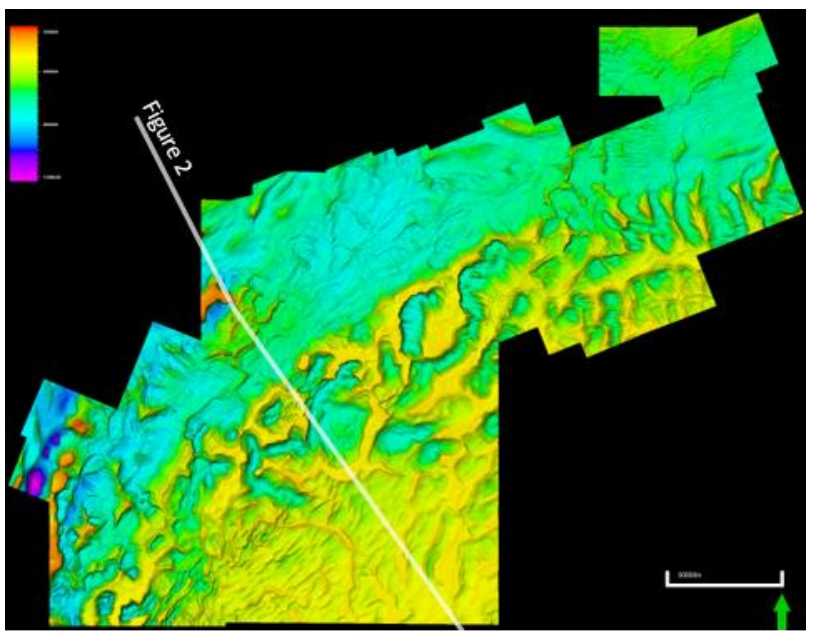

Figure 1 - Structural Map of the Top Salt clearly indicating the major tectono-stratigraphic units of the >44,000km2 study area: Merluza Graben, Albian Gap; Mini basin domain and fold belt domain.

In contrast to the passive behavior of the salt/LES on the Sao Paulo Plateau, the Merluza Graben reveals active diapirism and allochthonous salt sheets. The graben system is located inboard and separated from the Sao Paulo Plateau by normal faults that can exceed $3500 \mathrm{~m}$ in throw. It appears the faults have been active during the deposition of up to $4000 \mathrm{~m}$ of LES, while the plateau may have received about $1500 \mathrm{~m}$ of evaporite deposits. The grabens reveal a NNE-SSW trend, which is also reflected at the rugose base of the LES at the Sao Paulo Plateau where the fault system forms the grain of major pre-salt hydrocarbon reservoirs associated with carbonate buildups.

\section{Salt Flow Behavior}

The evaporite compositional layers reveal intensive heterogeneous (re-)folding that increases towards the top of the LES while its base appears undeformed. The latter is evident by flat reflectors associated with a prevalent 
basal anhydrite (Figure 3), merely disturbed by local instabilities, the late-stage faulting and associated pre-salt carbonate build-ups constituting the rugose morphology along the base of salt. The intensity of folding also decreases laterally with distance away from the Albian Gap and reaches quasi-original layering of about $1500 \mathrm{~m}$ in the most distal part. Accordingly the LES reaches maximum thickness of more than $3500 \mathrm{~m}$ in sections close to the Albian Gap where folding is most intense, inferring the highest heterogeneous deformation concentrates at the salt bulge next to the Albian Gap (Figure 2).

The critical sub-surface observations are based on high resolution enhanced seismic imaging of the salt and presalt section and well analysis. It indicates little to no lateral movement along the base of LES and provides no evidence for a distinguished detachment fault as suggested by common models accounting for the genesis of the Albian Gap (e.g. Rowan \& Ratliff 2012). The lateral flow component in the LES appears to be related to a continuous flow profile with particle movement increasing toward the top of the LES (Figure 3). The suggested process for the lateral flow in the LES is interpreted as displacement loading caused by the propagating sedimentary wedge forming the Albian Gap (Albertz \& Ings 2012).

The conclusions on the salt mechanical behavior in the Santos Basin have been facilitated by broadband seismic processing including FWI updates on the velocity model, which focus on the accurate post-salt velocities in conformance with the geological sub-surface architecture (Figure 4). In this context, it was key to capture the postsalt Albian carbonate as those form megaflaps flanking the salt at mini basins and are sensitive to significant velocity variation due to overburden pressure (Lebit et al 2018).

\section{Velocity Model Building}

The post-salt sediment velocity model building process utilized a combination of data driven traditional TTI tomography and Full Waveform Inversion (FWI). A proprietary, unique implementation of FWI, utilizing the full wave field, was deployed to push the velocity updates to $6 \mathrm{~km}$ of post-salt sediment cover (Ramos-Martinez et al. 2016). The result of this workflow was a geologically consistent post-salt sediment velocity model capturing accurately the depth dependent velocity variability of the Albian carbonates and within the mega-sequences of the Upper Cretaceous clastic sequences Figures 3 \& 4).

The Base of Salt was interpreted using seismic stack images in combination with offset/angle gathers at every image location from RTM migration.

Figure 2 - Regional Section through the inboard Merluza Graben and the outboard Sao Paulo Plateau; note the counter-regional throw between the Plateau and Graben that may exceed $3500 \mathrm{~m}$

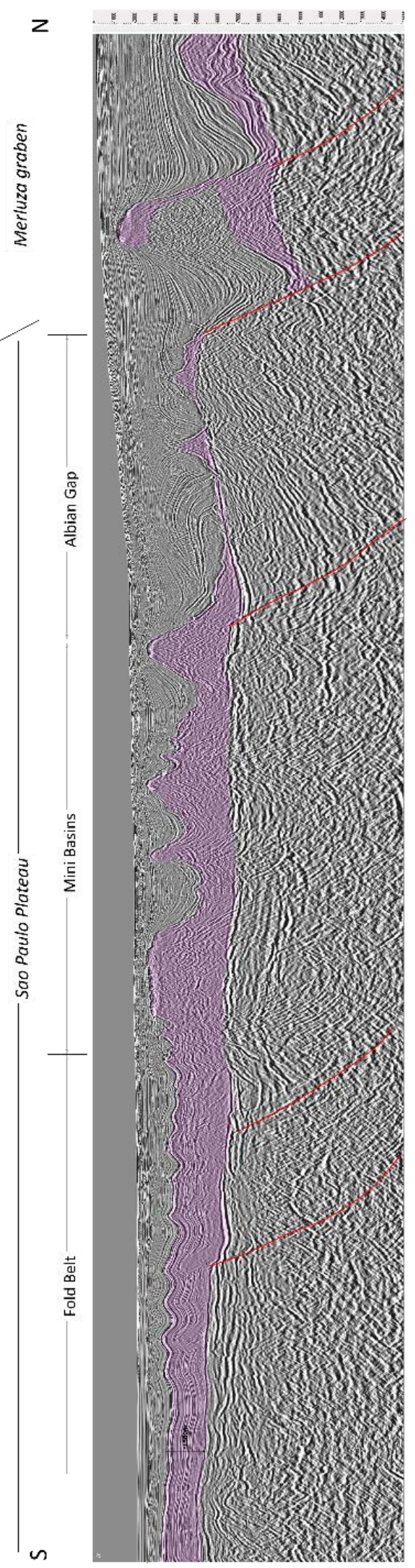


Following the positive results in post-salt sediments velocity updates, the FWI approach was extended to capture the velocity variations in the LES and sub-

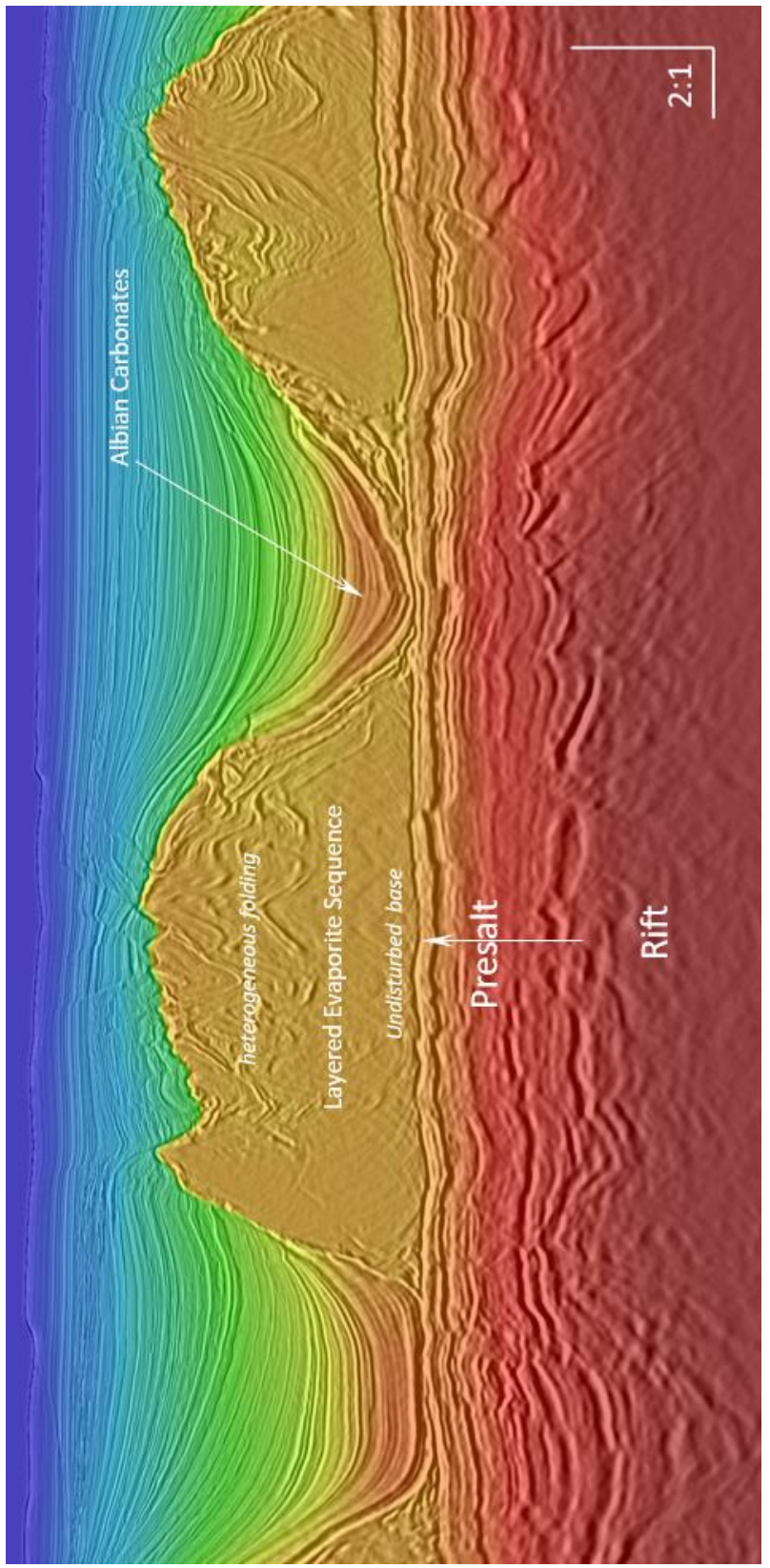

Figure 3 - Seismic Section (RTM) of the Mini Basin Domain with velocity overlay illustrating structural conformity of the model with the sub-surface geology

sequently to update the pre-salt velocities. This datadriven approach over $40,000 \mathrm{~km}^{2}$ generated continuous velocity model updates through the salt and into the presalt avoiding an imprecise horizon-based velocity boundary at the base of salt (Figure 3 ).

Enhanced imaging in Santos Basin, Brazil was achieved by utilizing a full bandwidth, Kirchhoff migration and a 35 $\mathrm{Hz}$ Reverse Time Migration (RTM); outputting angle gathers at every image location. Usage of angle gathers in the post-imaging workflows resulted in an excellent presalt image.

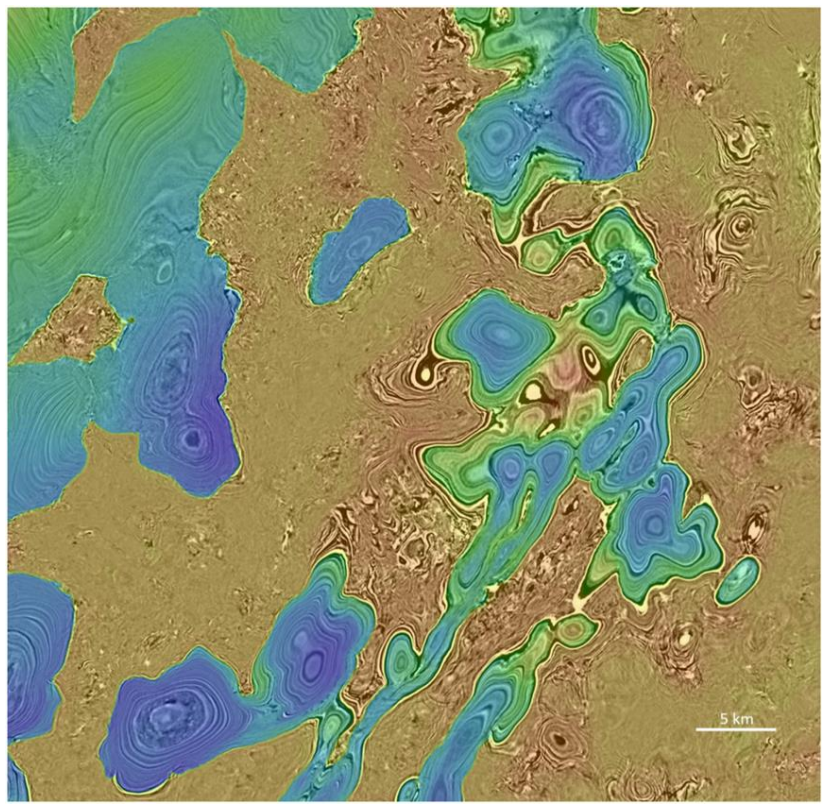

Figure 4 - Depth slice through RTM volume with velocity rendering, illustrates the structural conformity of the velocity model with the LES (brown) and the post-salt Albian carbonates (green to yellow).

\section{Least-Squares Migration}

Current imaging technologies (RTM, Kirchhoff Migration) provide a level of seismic resolution that suits the industry's expectation for capturing hydrocarbon reservoirs and outlining prospects. To obtain further resolution an iterative Least-squares migration approach was utilized to correct for acquisition effects, limited aperture and variable illumination (Korsmo \& Valenciano 2018, Lu et al. 2017). In this particular approach, the difference between the observed data and the synthetic data, modeled using a migrated stack and a velocity model, is minimized in a Least-squares sense to update the image.

The result of this application (Figure 5) was resolution enhancement of fault patterns in the shallow section, improved fold interference pattern within LES and a significant improvement in resolution of the reservoir carbonate section. The Least-squares migration stack also provides high granularity in attribute patterns that result in better definition of hydrocarbon reservoir targets (Figure 6).

The Least-squares migration (LSM) provides enhanced resolution of fault patterns to mitigate compartmentalization risk and enables seismic stratigraphy interpretation to characterize variation of the reservoir facies in the postsalt sequence, but most importantly in the prolific presalt play of the Santos Basin and elsewhere. 

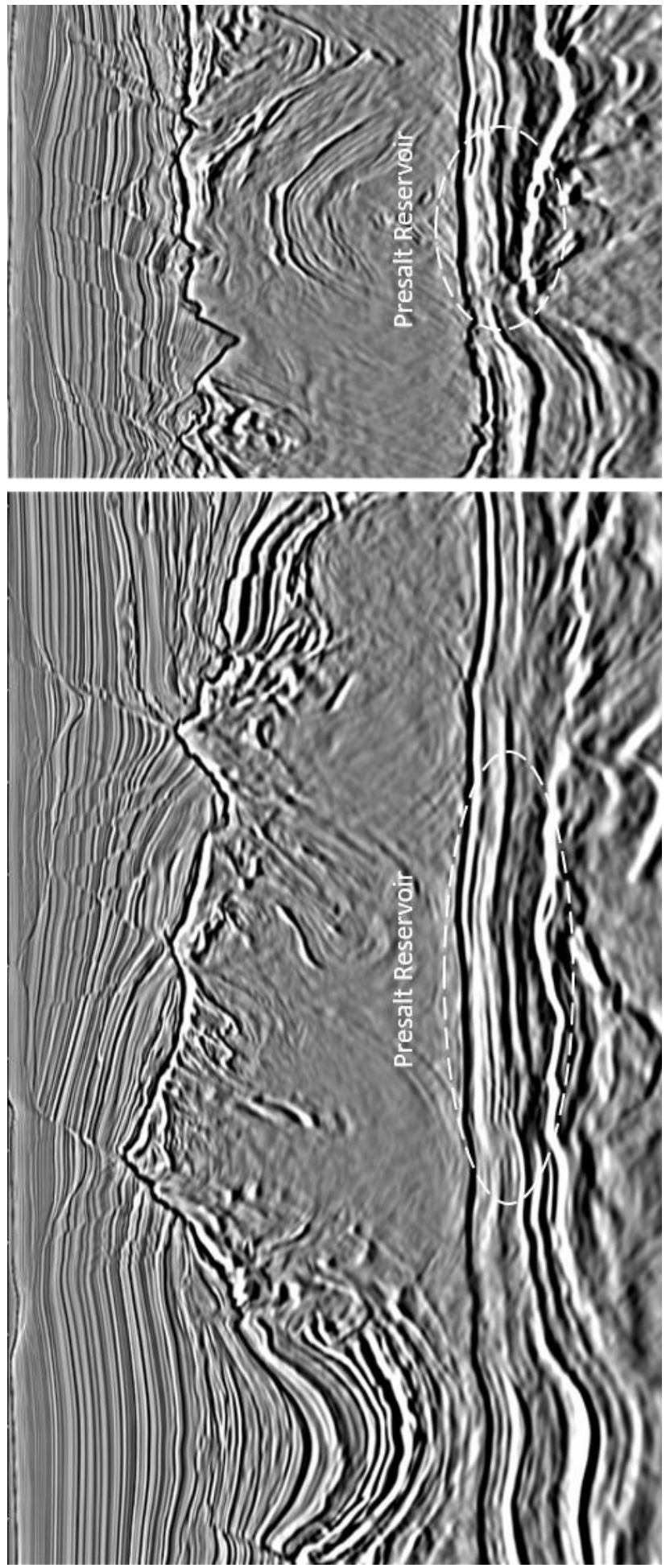

Figure 5A - Kirchhoff Migration filtered to the same bandwidth as $55 \mathrm{~Hz}$ Least-squares Migration (Figure 5B). Inlines \& Crosslines, respectively.
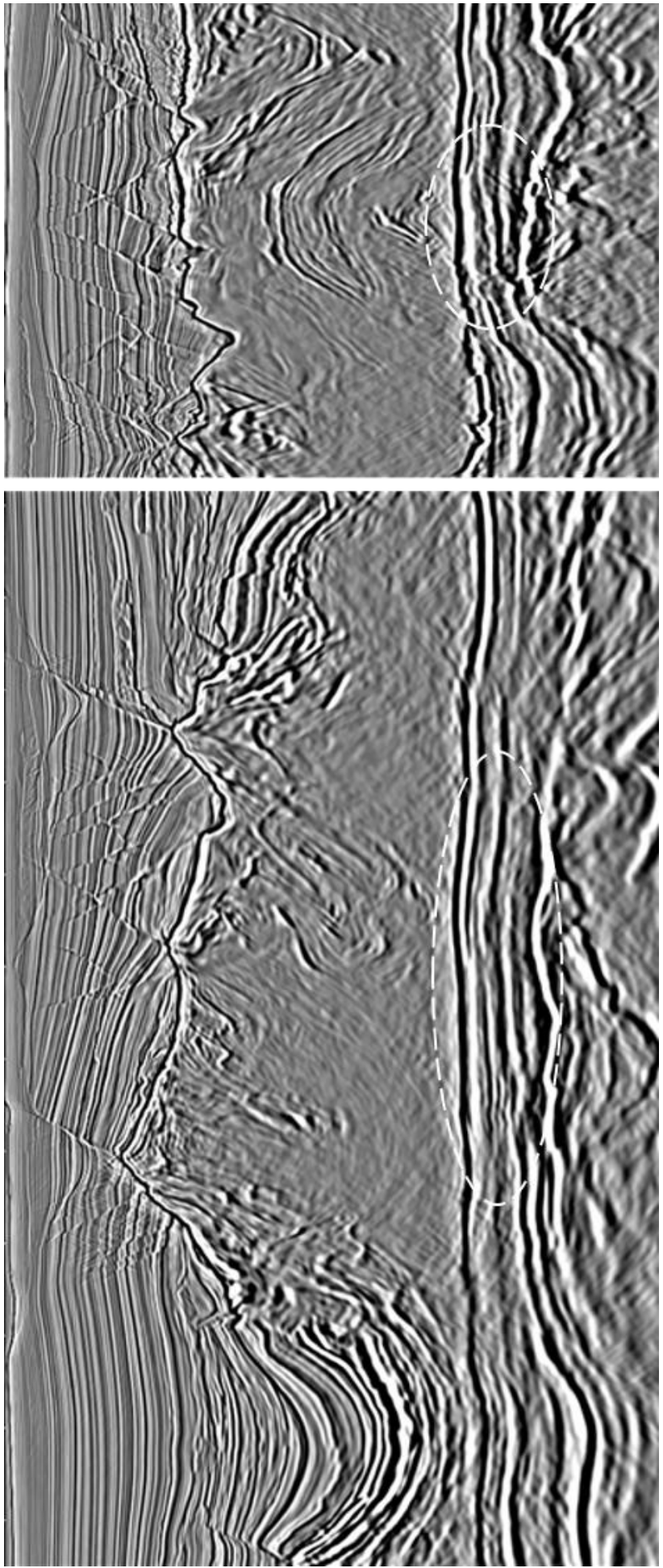

Figure 5B - Least-Squares Migration $(55 \mathrm{~Hz})$ illustrating the increase in postsalt imaging (faults and cap rocks), the resolution of salt internal structures and high resolution of the presalt reservoir sequence. 


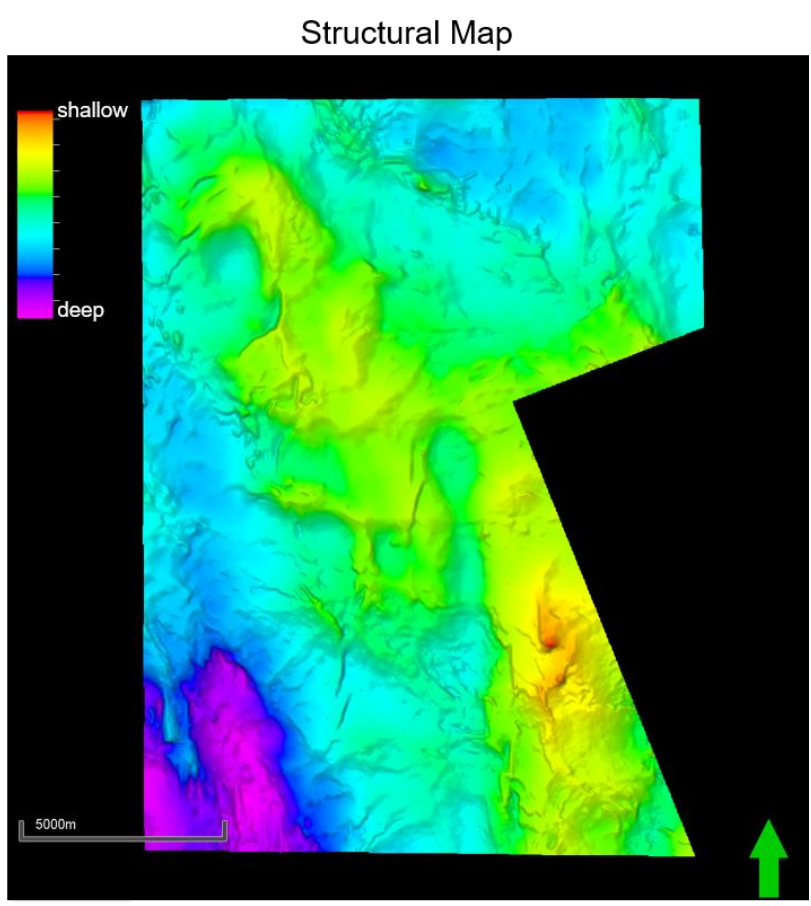

RMS Amplitude Map

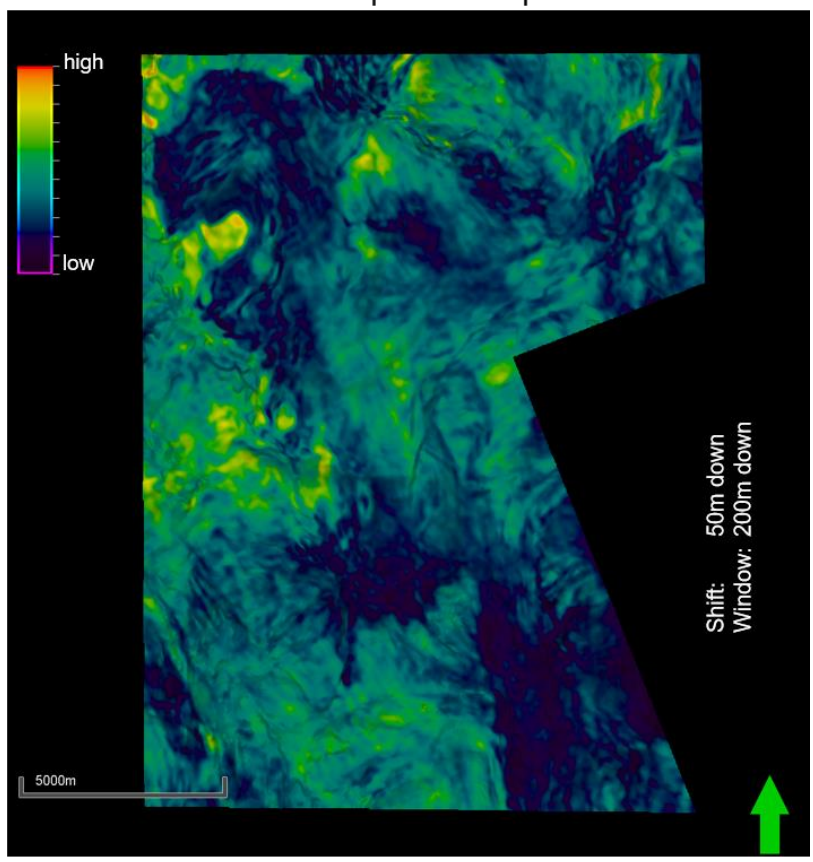

Figure 6A - Kirchhoff Migration: Structural Map of the base of the Aptian Salt (top) and a RMS amplitude (bottom) extraction within the pre-salt reservoir sequence over an $200 \mathrm{~m}$ interval $50 \mathrm{~m}$ below BoS. Hot colors indicate shallow depth and high RMS values while cold colors represent the opposite.
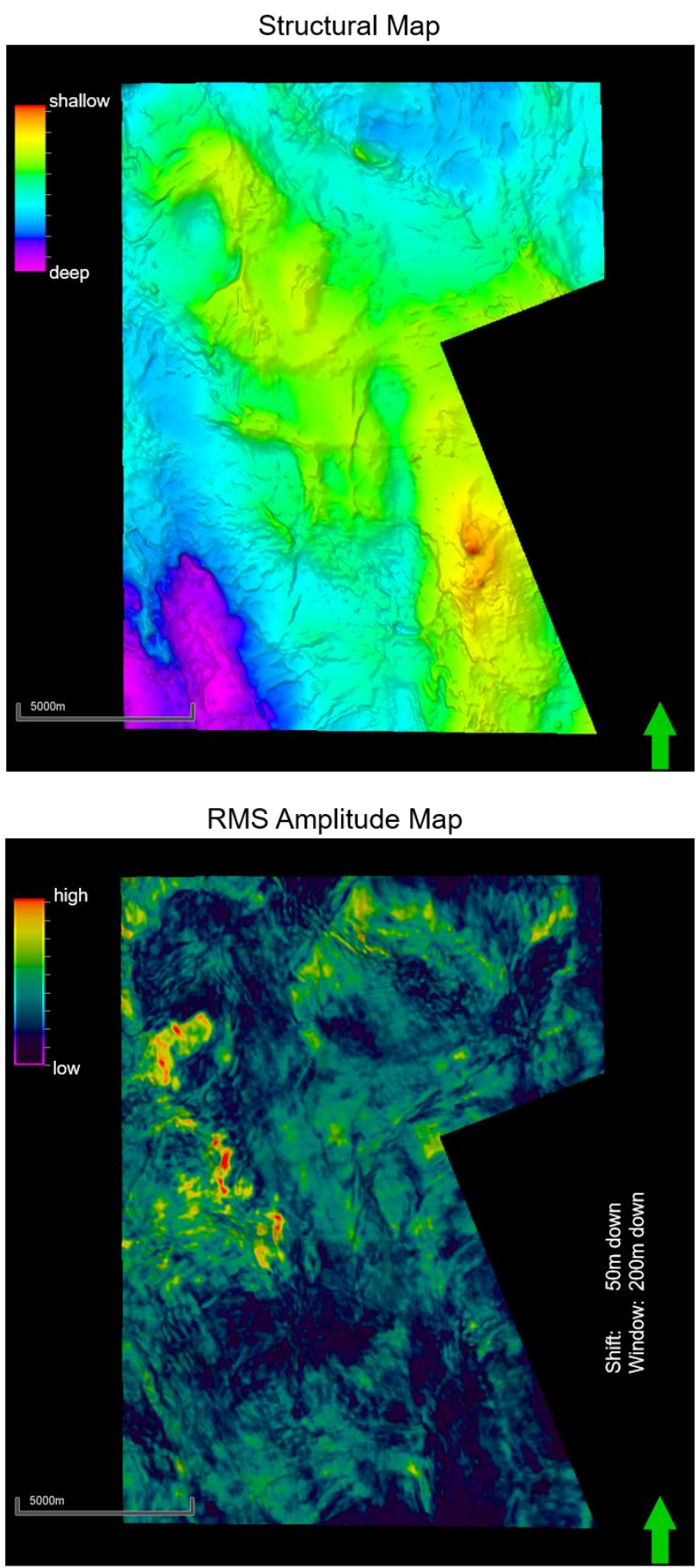

Figure 6B - Least Squares Migration: Structural Map of the base of the Aptian Salt (top) and a RMS amplitude (bottom) extraction within the pre-salt reservoir sequence over an $200 \mathrm{~m}$ interval $50 \mathrm{~m}$ below BoS. Hot colors indicate shallow depth and high RMS values while cold colors represent the opposite.

Note the enhancement in the spatial resolution of the structures and the improved resolution of the amplitude extraction with LSM. 


\section{Conclusions}

The study area of $44,000 \mathrm{~km}^{2}$ of the Santos Basin includes the largest 3D seismic migration volume ever with $34,000 \mathrm{~km}^{2}$ full fold coverage implementing innovative technologies including FWI for velocity model building. While benchmarking the velocity model against geological constraints was key to approach at an accurate model that result in excellent seismic resolution.

Recent Least Squares Migration efforts demonstrate an additional technology leap in advancing resolution over the entire seismic section including the presalt imaging.

The high resolution imaging of the salt (LES) internal structures indicate a heterogeneous flow pattern that originates at the salt base and increases upwards while the base itself lacks evidence of a continuous detachment surface. The cause of the flow/deformation within the Aptian layered evaporite sequence (LES) is attributed to displacement loading by a propagating sedimentary wedge forming the Albian Gap.

The rugosity at the base of the LES predominantly relates to late stage faulting and is locally enhanced by presalt carbonate build-ups forming the prolific presalt hydrocarbon reservoirs.

\section{Acknowledgments}

The authors thank PGS for the opportunity to present this work to the professional community.

\section{References}

ALBERTZ, M. \& INGS, S. Some consequences of mechanical stratification in basin-scale numerical models of passive margin salt tectonics. Geological Society London, Special Publication 363. P. 303-330. 2012

KORSMO, $\varnothing$. and VALENCIANO A., A.Iterative LeastSquares Migration in Practice, Application to a Narrow Azimuth North Sea Dataset. First EAGE/SBGF Workshop on Least-Squares Migration 2018

LEBIT, H., TILTON, J., ROY, N., OLLAGNON, P., ARASANIPALAI, S., OPDYKE, S. Revisiting Salt Mechanics in the Light of Enhanced Seismic Imaging in the Santos Basin, Brazil. AAPG 101 Annual Convention, abstract. Salt Lake City 2018.

LU, S., LI, X., Valenciano A., CHEMINGUI N., CHENG, C. Broadband Least-Squares Wave-Equation Migration. SEG International Exposition \& 87 $7^{\text {th }}$ Annual Meeting. 2017

MOHRIAK, W., SZATMARI, P., COUTO ANJOS S. M. Sal: Geoogia e Tectonica, 448 pp. Beca Edicoes Ltda Sao Paulo 2008
RAMOS-MARTINEZ, J., CRAWLEY, S., ZOU, Z., VALENCIANO, A.A., QUI, L. and CHEMINGUI, N. A Robust Gradient for Long Wavelength FWI Updates. 78th EAGE Conference and Exhibition, Expanded Abstracts, SRS2. 2016

ROWAN, M. \& RATLIFF, R. Cross-section restoration of salt-related deformation: Bets practices and pitfalls. Journal of Structural geology, 41, p. 24-37. 2012 